\title{
Thyrotropin Causes Dose-dependent Biphasic Regulation of cAMP Production Mediated by $\mathrm{G}_{\mathrm{s}}$ and $\mathrm{G}_{\mathrm{i} / \mathrm{o}}$ Proteins ${ }^{\mathrm{S}}$
}

\author{
Susanne Neumann, Sarah S. Malik, Bernice Marcus-Samuels, Elena Eliseeva, \\ Daesong Jang, Joanna Klubo-Gwiezdzinska, Christine C. Krieger, \\ and Marvin C. Gershengorn
}

Laboratory of Endocrinology and Receptor Biology (S.N., S.S.M., B.M.-S., E.E., D.J., C.C.K., M.C.G.) and Metabolic Disease Branch (J.K.-G.), National Institutes of Diabetes and Digestive and Kidney Diseases, National Institutes of Health, Bethesda, Maryland

Received May 23, 2019; accepted October 18, 2019

\section{ABSTRACT}

The thyrotropin (TSH) receptor (TSHR) signals via G proteins of all four classes and $\beta$-arrestin 1. Stimulation of TSHR leads to increasing CAMP production that has been reported as a monotonic dose-response curve that plateaus at high TSH doses. In HEK 293 cells overexpressing TSHRs (HEK-TSHR cells), we found that TSHR activation exhibits an "inverted U-shaped dose-response curve" with increasing cAMP production at low doses of TSH and decreased CAMP production at high doses $(>1 \mathrm{mU} / \mathrm{ml}$ ). Since protein kinase $\mathrm{A}$ inhibition by $\mathrm{H}-89$ and knockdown of $\beta$-arrestin 1 or $\beta$-arrestin 2 did not affect the decreased CAMP production at high TSH doses, we studied the roles of TSHR downregulation and of $G_{i} / G_{\circ}$ proteins. A high TSH dose $(100 \mathrm{mU} / \mathrm{ml})$ caused a $33 \%$ decrease in cell-surface TSHR. However, because inhibiting TSHR downregulation with combined expression of a dominant negative dynamin 1 and $\beta$-arrestin 2 knockdown had no effect, we concluded that downregulation is not involved in the biphasic cAMP response. Pertussis toxin, which inhibits activation of $G_{i} / G_{o}$, abolished the biphasic response with no statistically significant difference in cAMP levels at 1 and $100 \mathrm{mU} / \mathrm{ml} \mathrm{TSH}$. Concordantly, coknockdown of $G_{i} / G_{0}$ proteins increased cAMP levels stimulated by $100 \mathrm{mU} / \mathrm{ml}$ TSH from $55 \%$ to $73 \%$ of the peak level. These data show that biphasic regulation of CAMP production is mediated by $G_{s}$ and $G_{i} / G_{o}$ at low and high TSH doses, respectively, which may represent a mechanism to prevent overstimulation in TSHR-expressing cells.

\section{SIGNIFICANCE STATEMENT}

We demonstrate biphasic regulation of TSH-mediated CAMP production involving coupling of the TSH receptor (TSHR) to Gs at low TSH doses and to $\mathrm{G}_{\mathrm{i} / \mathrm{o}}$ at high TSH doses. We suggest that this biphasic cAMP response allows the TSHR to mediate responses at lower levels of TSH and that decreased CAMP production at high doses may represent a mechanism to prevent overstimulation of TSHR-expressing cells. This mechanism could prevent chronic stimulation of thyroid gland function.

\section{Introduction}

G protein-coupled receptors (GPCRs or seven-transmembrane-spanning receptors), like other receptor types, usually exhibit sigmoidal monotonic dose response curves that plateau at increasing doses when activated by their cognate ligands. However, it is now increasingly appreciated that receptor activators may generate nonmonotonic or hormetic, biphasic dose-response curves with stimulation of the response at low doses and decreased responses at high doses (Vandenberg et al., 2012; Calabrese, 2013). These types of response curves have been termed "inverted U-shaped dose

This work was supported by the Intramural Research Program of the National Institutes of Health National Institute of Diabetes and Digestive and Kidney Diseases [Grant Z01 DK011006].

https://doi.org/10.1124/mol.119.117382.

S This article has supplemental material available at molpharm. aspetjournals.org. response curves" (IUDRCs) and have been shown to be exhibited by several GPCRs, for example, the k-opioid receptor in peripheral sensory neurons (Jamshidi et al., 2015) or the dopamine $D_{1}$ receptor in the medial preoptic nucleus (Riters et al., 2014). Furthermore, a wide range of pharmaceutical products and approved drugs display biphasic dose responses (Calabrese, 2018). The biphasic dose response is becoming a central biologic concept due to its importance in dynamic processes of receptor activation as well as the impact on drug development regarding optimization of treatment (Calabrese, 2018).

GPCRs are capable of coupling to and activating multiple G proteins (Rashid et al., 2004; Woehler and Ponimaskin, 2009). The human thyrotropin (TSH) receptor (TSHR), when activated by its native ligand TSH, controls development and function of the thyroid. The TSHR can couple to members of all four G protein classes (Laugwitz et al., 1996). In Chinese

ABBREVIATIONS: bTSH, bovine TSH; DMEM, Dulbecco's modified Eagle's medium; FACS, fluorescence-activated cell sorting; FBS, fetal bovine serum; GPCR, G protein-coupled receptor; HBSS, Hanks' balanced salt solution; HEK cells, human embryonic kidney cells; IBMX, 3isobutyl-1-methylxanthine; IUDRC, inverted U-shaped dose response curve; PBS, phosphate-buffered saline; PTX, pertussis toxin; rhTSH, recombinant human TSH; siRNA, small interfering RNA; TSH, thyrotropin; TSHR, TSH receptor. 
hamster ovary cells overexpressing TSHR, TSH regulation of mitogen-activated kinase 8 activity exhibits an IUDRC in which $\mathrm{G}_{\mathrm{i}}$ activates protein kinase $\mathrm{C}$ that mediates the increasing phase at low doses and $G_{\mathrm{S}}$ stimulates cAMP production that, in turn, activates protein kinase $\mathrm{A}$ that mediates the decreasing phase at high doses (Hara et al., 1999). However, to our knowledge, biphasic regulation of cAMP production by increasing doses of an agonist acting at the TSHR and being mediated by $G_{s}$ and $G_{i / o}$ proteins has not been reported. Specifically, TSHR may couple to $\mathrm{G}_{\mathrm{s}}$ to activate adenylate cyclase and increase cAMP production (Allgeier et al., 1994) at low agonist doses and to $\mathrm{G}_{\mathrm{i}} / \mathrm{G}_{\mathrm{o}}$ to inhibit adenylate cyclase and decrease cAMP production at high doses. Indeed, we previously showed that TSHR couples to $\mathrm{G}_{\mathrm{q}}$ to activate phospholipase $\mathrm{C}$ to stimulate inositol-1,4,5-trisphosphate production with a 100 -fold lower potency $\left(\mathrm{EC}_{50}\right)$ for $\mathrm{TSH}$ compared with $\mathrm{G}_{\mathrm{s}}$ activation (Allen et al., 2011). We found that activation of HEK 293 cells stably expressing the TSHR (HEK-TSHR cells) with TSH and thyrostimulin (a second TSHR cognate ligand) (Nakabayashi et al., 2002; Karponis and Ananth, 2017) exhibits IUDRC regulation of cAMP production. We show that this biphasic regulation occurs via activation of $\mathrm{G}_{\mathrm{s}}$ at low doses and by $\mathrm{G}_{\mathrm{i}} \mathrm{G}_{\mathrm{o}}$ at high doses of TSHR ligands.

\section{Materials and Methods}

Materials. Dulbecco's modified Eagle's medium (DMEM), 100-fold penicillin-streptomycin solution, 1 M HEPES buffer, phosphatebuffered saline (PBS), and Hanks' balanced salt solution (HBSS) were obtained from Mediatech Inc. (Manassas, VA). H-89 was purchased from Selleckchem (Houston, TX). X-treme Gene 9 DNA transfection reagent and 3-isobutyl-1-methylxanthine (IBMX) were purchased from Sigma-Aldrich (St. Louis, MO). Pertussis toxin (PTX) was obtained from Invitrogen (Carlsbad, CA). Bovine TSH was obtained from Merck Millipore (cat. no. 609385; Darmstadt, Germany) and from SigmaAldrich (cat. no. T8391). Recombinant human TSH (thyrotropin alfa, Thyrogen) was purchased from Sanofi Genzyme (Cambridge, MA). Hyclone-fetal bovine serum (FBS) was obtained from GE Healthcare (Logan, UT). Hygromycin B, human GNAS, GNAZ, GNAO1, GNAI1, GNAI2, GNAI3, ARRB1, and ARRB2 ON-TARGET plus siRNAs and ON-TARGET plus non-targeting pool siRNA (scrambled siRNA), DharmaFECT 1 transfection reagent, the cAMP-Screen chemiluminescent immunoassay system, and the Alexa Fluor 647 antibody labeling kit were purchased from Thermo Fisher Scientific Inc. (Waltham, MA). Accutase was obtained from Innovative Cell Technologies (San Diego, CA). EGTA was purchased from Alfa Aesar (Tewksbury, MA). EDTA was obtained from Quality Biologic (Gaithersburg, MD). The dominant negative dynamin $1 \mathrm{~K} 44 \mathrm{~A}$ pEGFP was purchased from Addgene (plasmid \#34681; Addgene, Watertown, MA). The plasmid was deposited by Sandra Schmid (Song et al., 2004). The TSHR antibody KSAb1 was kindly provided by Dr. Paul Banga.

Cell Culture. HEK 293 cells stably expressing the TSHR (HEKTSHR cells) were generated as previously described (Neumann et al., 2008). HEK-TSHR cells were grown in DMEM supplemented with $10 \%$ fetal bovine serum, penicillin $(100 \mathrm{U} / \mathrm{ml})$, and streptomycin $(100 \mu \mathrm{g} / \mathrm{ml})$ at $37^{\circ} \mathrm{C}$ in a humidified $5 \% \mathrm{CO}_{2}$ incubator. Hygromycin $(250 \mu \mathrm{g} / \mathrm{ml})$ was used as a selection marker.

Measurement of cAMP Production. In general, untreated or treated HEK-TSHR cells were seeded 24 hours before the stimulation with ligands bovine TSH (bTSH), recombinant human TSH (rhTSH) or thyrostimulin. The seeding density varied based on the experiment. Before ligand stimulation, the cells were washed once with HBSS/ $10 \mathrm{mM}$ HEPES and incubated for 30 minutes at $37^{\circ} \mathrm{C}$. Subsequently, the buffer was removed and replaced with HBSS/10 mM HEPES containing $1 \mathrm{mM}$ 3-isobutyl-1-methylxanthine (IBMX) and cells were incubated with the ligand(s) in a humidified $5 \% \mathrm{CO}_{2}$ incubator at $37^{\circ} \mathrm{C}$ for 60 minutes or as otherwise indicated. Following aspiration of the medium, cells were lysed using lysis buffer of the cAMP-Screen chemiluminescent immunoassay system. The cAMP content of the cell lysate was determined using the method described in the manufacturer's protocol. The potencies (i.e., $\mathrm{EC}_{50}$ ) of the ligands were obtained from the dose-response curves using GraphPad Prism Version 7 for Windows (GraphPad Software, La Jolla, CA).

Time Course to Determine the Kinetics of cAMP Production at Low and High TSH Doses. For the time course experiments, HEK-TSHR cells were seeded in 48-well plates at a density of $1.2 \times 10^{5}$ cells per well. Twenty-four hours after seeding, cells were incubated for an additional 30 minutes in HBSS/10 mM HEPES prior to stimulation.

In the first experiment, HEK-TSHR cells were treated in HBSS/ $10 \mathrm{mM}$ HEPES with $1 \mathrm{mM}$ IBMX and $1 \mathrm{mU} / \mathrm{ml}$ TSH (low dose) or $100 \mathrm{mU} / \mathrm{ml} \mathrm{TSH}$ (high dose) simultaneously for up to 12.5 minutes. cAMP production was measured at $2.5,5,7.5,10$, and 12.5 minutes. In the second experiment, HEK-TSHR cells were pretreated with $1 \mathrm{mU} / \mathrm{ml} \mathrm{TSH}$ and $100 \mathrm{mU} / \mathrm{ml} \mathrm{TSH}$ in the absence of IBMX for 20 minutes. Subsequently, the medium was removed and replaced with HBSS $/ 10 \mathrm{mM}$ HEPES/ $1 \mathrm{mM}$ IBMX with 1 or $100 \mathrm{mU} / \mathrm{ml}$ TSH and time points were taken at $22.5,25,27.5,30$, and 32.5 minutes after the incubation with TSH was started to determine the rate of cAMP production.

Treatment with Pertussis Toxin. HEK-TSHR cells were seeded at $1.2 \times 10^{5}$ cells per well in DMEM with $10 \%$ FBS in 48 -well plates and cultured overnight. Twenty-four hours later the medium was removed, and the cells were exposed to $100 \mathrm{ng} / \mathrm{ml}$ PTX in DMEM with $10 \%$ FBS or in medium only (control) for 24 hours. The next day, the medium was removed, and the cells were washed with HBSS/10 mM HEPES and then incubated with increasing doses of bTSH $(0-300 \mathrm{mU} / \mathrm{ml})$ in HBSS $/ 10 \mathrm{mM}$ HEPES/1 mM IBMX for 1 hour at $37^{\circ} \mathrm{C}$. Subsequently, the cells were lysed, and cAMP production was determined as described above.

Transfection with Dynamin 1 K44A Plasmid and ARRB2 siRNA. HEK-TSHR cells were seeded at $5 \times 10^{6}$ cells per well in DMEM with $10 \%$ FBS in 10-cm dishes. Twenty-four hours later, the cells were transfected with ARRB2 ( $\beta$-arrestin 2 ) siRNA or nontargeting pool siRNA using DharmaFECT 1 transfection reagent per the manufacturer's instructions. Two hours later, the cells were transfected with Dynamin 1 K44A pEGFP or the pEFGP control vector using $\mathrm{X}$-treme Gene 9 DNA transfection reagent. Twenty-four hours later, cells were harvested and $1.2 \times 10^{5}$ cells per well were seeded in 48-well plates for cAMP measurement, and $1.8 \times 10^{6}$ cells per well were seeded in six-well plates for fluorescence-activated cell sorting (FACS) analysis of TSHR cells surface expression. After a 24-hour incubation, the cells for cAMP measurement were washed with HBSS $/ 10 \mathrm{mM}$ HEPES and incubated for 30 minutes at $37^{\circ} \mathrm{C}$. Subsequently, the medium was removed and replaced with HBSS/ $10 \mathrm{mM}$ HEPES/ $1 \mathrm{mM}$ IBMX with $100 \mathrm{mU} / \mathrm{ml} \mathrm{bTSH}$. The cells were incubated for 1 hour at $37^{\circ} \mathrm{C}$ and then lysed and analyzed for cAMP production as described above. The measurement of TSHR cell surface expression was carried out as described below.

Measurement of TSHR Cell Surface Expression. TSHR cell surface expression was determined using FACS. Alexa Fluor 647 was directly conjugated to the activating TSHR antibody KSAb1 (KSAb1647) according to manufacturer's directions using the Alexa Fluor 647 antibody labeling kit.

HEK-TSHR cells were seeded and transfected as described above with dynamin $1 \mathrm{~K} 44 \mathrm{~A}$ and ARRB2 siRNA. Forty-eight hours after transfection, cells were stimulated with $100 \mathrm{mU} / \mathrm{ml} \mathrm{bTSH}$ for 1 hour at $37^{\circ} \mathrm{C}$. Subsequently, cells were harvested on ice with Accutase according to the manufacturer's directions. Cells were washed with PBS and resuspended to a concentration of $1 \times 10^{6}$ cells $/ \mathrm{ml}$ in ice-cold PBS with 5\% FBS. KSAb1-647 was added to cells to a final concentration of $5 \mu \mathrm{g} / \mathrm{ml}$. Cells were incubated for 2 hours on ice with mixing every 15 minutes. After the incubation, cells were washed three times in PBS with $1 \%$ BSA. Subsequently, cells were resuspended in PBS with $1 \% \mathrm{BSA}$ and subjected to flow cytometric analysis on a BD 


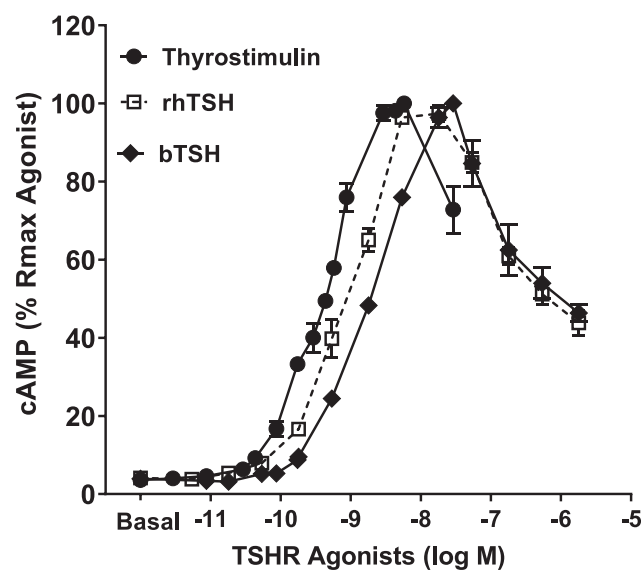

Fig. 1. bTSH, rhTSH, and thyrostimulin caused inverted U-shaped dose response regulation of cAMP production. HEK-TSHR cells were incubated with increasing doses of bTSH, rhTSH $[0-300 \mathrm{mU} / \mathrm{ml}(5.4 \mu \mathrm{M})]$, or thyrostimulin [0-1000 $\mathrm{ng} / \mathrm{ml}(29 \mathrm{nM})]$ in HBSS/HEPES with IBMX at $37^{\circ} \mathrm{C}$ for 60 minutes. After incubation with ligands, HEK-TSHR cells were lysed and cAMP was measured in the cell lysates. The symbols represent the mean \pm S.E.M. of duplicate measurements in three experiments. Rmax, maximum response.

FACSAria II (BD Biosciences, Franklin Lakes, NJ). Viable cells were gated based on forward light scatter, and data were analyzed with BD FACS Diva software.

Transfection of HEK-TSHR Cells with siRNA Targeting $\mathbf{G}_{\mathrm{s}}$, $\mathbf{G}_{\mathbf{z}}, \mathbf{G}_{\mathbf{i 1}, 2,3}, \mathbf{G}_{\mathbf{o 1}}, \boldsymbol{\beta}$-Arrestin 1, and $\boldsymbol{\beta}$-Arrestin 2. HEK-TSHR cells were seeded in DMEM with $10 \%$ FBS into $100 \mathrm{~mm}$ dishes at $4 \times 10^{6}$ cells per dish. After 24 hours, the cells were cotransfected with ONTARGETplus human GNAS $\left(\mathrm{G}_{\mathrm{s}}\right)$, GNAZ $\left(\mathrm{G}_{\mathrm{z}}\right)$, GNAI1 $\left(\mathrm{G}_{\mathrm{i} 1}\right)$, GNAI2 $\left(\mathrm{G}_{\mathrm{i} 2}\right)$, GNAI3 $\left(\mathrm{G}_{\mathrm{i} 3}\right)$, and GNAO1 $\left(\mathrm{G}_{\mathrm{o} 1}\right)$ siRNA or cotransfected with ARRB1 ( $\beta$-arrestin 1$)$ and ARRB2 $(\beta$-arrestin 2$)$ siRNA or ONTARGET plus non-targeting pool siRNA using DharmaFECT 1 transfection reagent per the manufacturer's instructions. Forty-eight hours after transfection, cells were harvested and seeded in a 48-well plate at $1.2 \times 10^{5}$ cells per well. Twenty-four hours after seeding, the cells were stimulated with increasing doses of TSH for a dose-response curve or with two doses, 1 or $100 \mathrm{mU} / \mathrm{ml} \mathrm{bTSH}$, for 1 hour. Subsequently, the cells were lysed and assayed by enzyme-linked immunosorbent assay to measure cAMP production as described above.

Quantitative Real-time Polymerase Chain Reaction. Total RNA was purified using RNeasy Mini Kits (Qiagen Inc., Valencia, CA). First-strand cDNA was prepared using a High Capacity cDNA Reverse Transcription Kit (Life Technologies Corporation, Waltham, MA). Real-time polymerase chain reaction was performed in $25 \mu \mathrm{l}$ reactions using cDNA prepared from $100 \mathrm{ng}$ or less of total RNA and TaqMan Universal PCR Master Mix (Life Technologies Corporation). mRNA expression of GNAS, GNAZ, GNAI1, GNAI2, GNAI3, GNAO, ARRB1, and ARRB2 was measured using primers and probes from Life Technologies Corporation. Quantitative real-time polymerase chain reaction results were normalized to glyceraldehyde 3-phosphate dehydrogenase to correct for differences in RNA input.

Data and Statistical Analysis. Data analysis was performed with GraphPad Prism Version 7 for Windows (GraphPad Software). Data are expressed as mean \pm S.E. The data were analyzed by unpaired two-tailed $t$ test.

\section{Results}

Stimulation of the TSHR by three natural agonists, rhTSH, bTSH, and thyrostimulin, led to IUDRCs for cAMP production (Fig. 1). In the first phase of the curve, TSH concentration from 0 to $1 \mathrm{mU} / \mathrm{ml}(18 \mathrm{nM})$ and thyrostimulin concentration from 0 to $100 \mathrm{ng} / \mathrm{ml}(2.9 \mathrm{nM})$ induced an increase in cAMP production, while rhTSH, bTSH, and thyrostimulin above these concentrations decreased cAMP production.

These experiments were performed in the presence of the cAMP phosphodiesterase inhibitor IBMX and, therefore, likely represent effects on cAMP production rather than degradation. The three agonists caused virtually identical maximal increases in cAMP production with $\mathrm{EC}_{50}$ values for these increases that are within fivefold of each other $\left(\mathrm{EC}_{50}\right.$ values for thyrostimulin, rhTSH, and bTSH are $0.5,1$, and $2.5 \mathrm{nM}$, respectively). The decrease in cAMP at doses above $1 \mathrm{mU} / \mathrm{ml}$ is similar for rhTSH and bTSH; we do not have sufficient amounts of thyrostimulin to test higher doses.

Subsequent studies focused on the characterization of the molecular mechanisms underlying the TSHR- mediated IUDRC for cAMP production. First, we confirmed in HEKTSHR cells by knockdown of Gs that the increasing levels of cAMP at low doses of TSH were mediated by $\mathrm{G}_{\mathrm{s}}$ activation of adenylyl cyclase (Fig. 2). The knockdown of Gs (knockdown efficiency of $63 \% \pm 2.5 \%$ ) decreased the maximum cAMP production at $1 \mathrm{mU} / \mathrm{ml}$ of TSH by $61 \% \pm 5.1 \%$. To confirm that the decreasing cAMP levels at high TSH doses (above $1 \mathrm{mU} / \mathrm{ml}$ ) were caused by decreasing cAMP production and not by degradation, we performed experiments comparing the time courses of the effects of $1 \mathrm{mU} / \mathrm{ml} \mathrm{bTSH}$ (low dose, $18 \mathrm{nM}$ ) and $100 \mathrm{mU} / \mathrm{ml} \mathrm{bTSH}$ (high dose, $1.8 \mu \mathrm{M}$ ). In the presence of IBMX, $100 \mathrm{mU} / \mathrm{ml} \mathrm{bTSH}$ caused a more rapid increase in cAMP levels than $1 \mathrm{mU} / \mathrm{ml}$ bTSH (Fig. 3A) but the rate of increase fell below that of $1 \mathrm{mU} / \mathrm{ml}$ after 20 minutes (Fig. 3B). This suggested that the early effects of bTSH were mediated by similar mechanisms, most likely rapid coupling of TSHR to $\mathrm{G}_{\mathrm{s}}$ as shown previously (Laugwitz et al., 1996), in which higher levels of TSHR occupancy occurred at early times with 100 $\mathrm{mU} / \mathrm{ml} \mathrm{bTSH}$ than $1 \mathrm{mU} / \mathrm{ml} \mathrm{bTSH}$, followed by a second effect

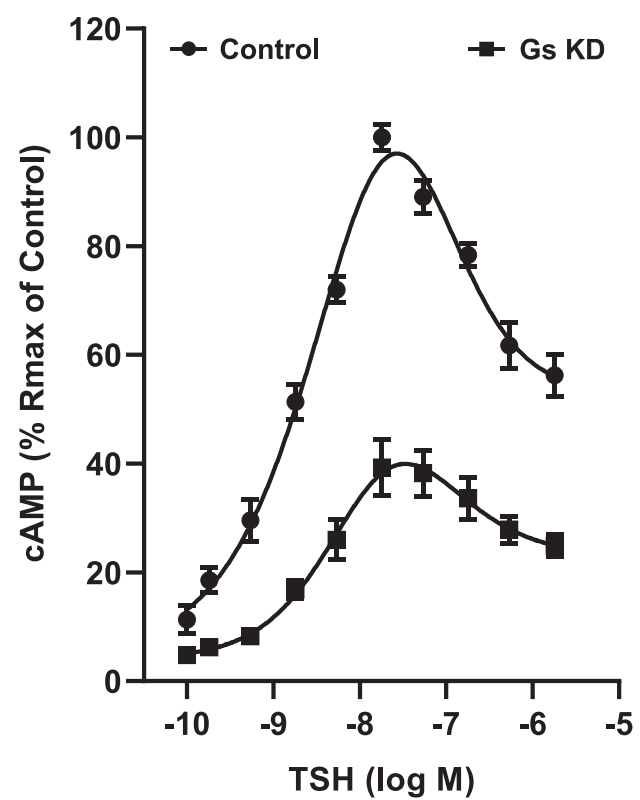

Fig. 2. Biphasic regulation of cAMP production persists after knockdown of $\mathrm{G}_{\mathrm{s}}$. HEK-TSHR cells were transfected with human GNAS $\left(\mathrm{G}_{\mathrm{s}}\right)$ siRNA. Control cells were transfected with non-targeting pool siRNA. Seventy-two hours after transfection, the cells were stimulated with increasing doses of TSH for 1 hour. Subsequently, the cells were lysed, and cAMP production was determined. The data represent the mean \pm S.E.M. of three experiments in duplicate. KD, Knockdown. 

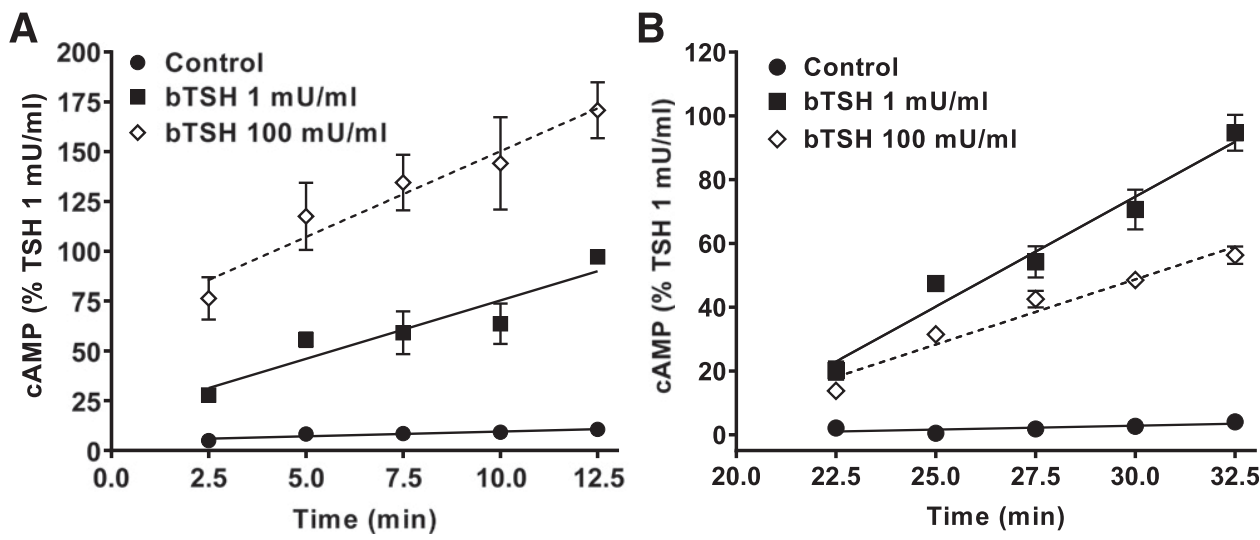

Fig. 3. The time course of cAMP production. (A) HEK-TSHR cells were treated with $1 \mathrm{mU} / \mathrm{ml}$ (18 $\mathrm{nM}$ ) or $100 \mathrm{mU} / \mathrm{ml}(1.8 \mu \mathrm{M}) \mathrm{TSH}$ in HBSS/HEPES/ IBMX for up to 12.5 minutes. The cell samples for each time point were lysed starting at 2.5 minutes in 2.5 -minute intervals until 12.5 minutes, and cAMP was measured in these cell lysates. (B) Cells were pretreated without or with 1 or $100 \mathrm{mU} / \mathrm{ml} \mathrm{bTSH}$ in HBSS/HEPES at $37^{\circ} \mathrm{C}$. After $20 \mathrm{minutes}$, the media were removed and replaced by HBSS/HEPES with IBMX containing the same concentrations of bTSH. The cell samples for each time point were lysed starting at 22.5 minutes in 2.5-minute intervals until 32.5 minutes, and cAMP was analyzed in these cell lysates. The symbols represent the means of duplicate or triplicate measurements in three experiments. The rate of cAMP production is decreased by pretreatment with $100 \mathrm{mU} / \mathrm{ml}$ compared with $1 \mathrm{mU} / \mathrm{ml}$ bTSH. Statistical significance was determined by unpaired two-tailed $t$ test. The rates of cAMP production were statistically different $(P<0.05)$.

at later time points. To show this directly, we pretreated cells with 1 or $100 \mathrm{mU} / \mathrm{ml}$ bTSH in the absence of IBMX for 20 minutes, and then with bTSH in the presence of IBMX for another 12.5 minutes and measured the rates of cAMP production (Fig. 3B). Between 20 and 32.5 minutes, the rate of cAMP production caused by $100 \mathrm{mU} / \mathrm{ml}$ bTSH was $60 \%$ of that stimulated by $1 \mathrm{mU} / \mathrm{ml}$ bTSH.

Next, we asked whether homologous desensitization by $\beta$-arrestin 1 or $\beta$-arrestin 2 or heterologous desensitization by protein kinase A was involved in the decrease in cAMP production at high TSH doses, we studied the effects of $\beta$-arrestin 1 and 2 knockdown by siRNAs and protein kinase A inhibition by H-89 on cAMP production. Neither $\beta$-arrestin 1 and 2 knockdown nor H-89 inhibited the decrease in cAMP production by high doses of TSH but H-89 increased the maximal stimulation by low doses of TSH (Supplemental Figs. 1 and 2).

TSHR downregulation was considered as another potential factor for the decreased cAMP production at high doses of TSH. Therefore, we measured surface expression of TSHR by FACS. Treatment with $100 \mathrm{mU} / \mathrm{ml}$ bTSH caused a $33 \% \pm$ $3.4 \%$ decrease in surface TSHR after 1 hour (Fig. 4A). Dynamin $1 \mathrm{~K} 44 \mathrm{~A}$ is a GTPase defective mutant that abolishes clathrin-mediated endocytosis (Song et al., 2004). It has been shown that $\beta$-arrestin 2 has a predominant role in TSHR internalization and desensitization (Frenzel et al., 2006; Boutin et al., 2014). Transfection with ARRB2 siRNA led to a $78.3 \% \pm 1.5 \%$ decrease in $\beta$-arrestin 2 mRNA expression.
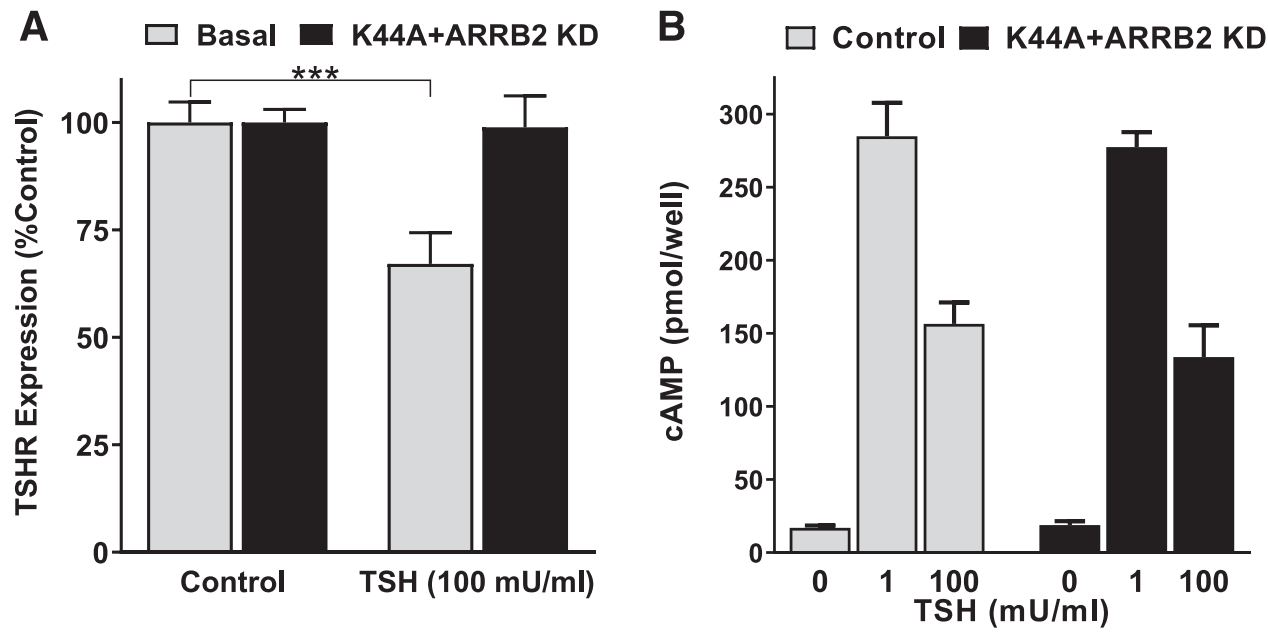

Fig. 4. Downregulation of TSHR cell surface expression did not affect decreased cAMP production caused by $100 \mathrm{mU} / \mathrm{ml} \mathrm{bTSH}$. (A) TSHR cell surface expression in HEK-TSHR cells was measured by FACS after a 60 -minute incubation without (basal) or with $100 \mathrm{mU} / \mathrm{ml}(1.8 \mu \mathrm{M}) \mathrm{bTSH}$ in control cells or cells transfected 2 days before with a plasmid that expresses the dominant negative dynamin 1 K44A mutant and with ARRB2 ( $\beta$-arrestin 2 ) siRNA. Expression of dynamin $1 \mathrm{~K} 44 \mathrm{~A}$ and knockdown of $\beta$-arrestin 2 inhibited downregulation of TSHR cell surface expression. The bars represent mean with $95 \%$ confidence interval of duplicate or triplicate measurements in four FACS experiments. Statistical significance was determined by unpaired twotailed $t$ test $(* * * P<0.001)$. (B) In parallel to the FACS analysis, cAMP production was measured in control and transfected HEK-TSHR cells. The cells were incubated for 60 minutes with $100 \mathrm{mU} / \mathrm{ml} \mathrm{TSH}$ in HBSS/HEPES/IBMX. Subsequently, the cells were lysed and cAMP production was analyzed. The bars represent mean with $95 \%$ confidence interval. There was no statistically significant difference determined by unpaired two-tailed $t$ test between cells transfected with the dynamin $1 \mathrm{~K} 44 \mathrm{~A}$ mutant and ARRB2 siRNA and nontreated cells (control). $\mathrm{KD}$, knockdown. 
The combination of pre-expressing the dominant negative dynamin $1 \mathrm{~K} 44 \mathrm{~A}$ mutant and pretreating the cells with ARRB2 siRNA abolished the decrease in cell surface expression by $100 \mathrm{mU} / \mathrm{ml}$ TSH. In conclusion, the inhibition of TSHR downregulation had no effect on the decrease in cAMP production caused by $100 \mathrm{mU} / \mathrm{ml}$ bTSH compared with $1 \mathrm{mU} / \mathrm{ml}$ bTSH (Fig. 4B).

We then studied whether $G_{i} / G_{o}$ proteins may be involved in the IUDRC by measuring the effects of pertussis toxin (PTX), which inhibits TSHR activation of $\mathrm{G}_{\mathrm{i}} / \mathrm{G}_{\mathrm{o}}$. PTX had no effect on the increase in cAMP production in the first phase of the curve at low TSH doses but it inhibited the decrease in cAMP at high TSH doses (Fig. 5A). PTX inhibited the decrease in cAMP levels at $100 \mathrm{mU} / \mathrm{ml} \mathrm{TSH}$ from $63 \% \pm 2.0 \%$ to $89 \% \pm 1.8 \%$ (Fig. 5, A and B) of the peak level at $1 \mathrm{mU} / \mathrm{ml}$ of the nontreated control. However, PTX treatment led to a small overall decrease in cAMP production. Therefore, we also compared the cAMP production at 1 and $100 \mathrm{mU} / \mathrm{ml}$ in PTX-treated cells only. The compilation of all values in PTX-treated samples (Fig. 5, A and B) showed no significant difference between 1 and $100 \mathrm{mU} / \mathrm{ml}(93 \% \pm 2.1 \%$ and $89 \% \pm 1.8 \%$, respectively, of peak cAMP production of the nontreated control). PTX abolished the biphasic response indicating the involvement of $\mathrm{G}_{\mathrm{i} / \mathrm{o}}$ in the inhibition of cAMP at high TSH doses. Furthermore, we tested a potential effect of $\mathrm{G}_{\mathrm{z}}$, which is the only PTXinsensitive member of the inhibitory $\mathrm{G}_{\mathrm{i}}$ protein family (Casey et al., 1990). The knockdown efficiency for $\mathrm{G}_{\mathrm{z}}$ was $70.7 \% \pm$ $3.8 \%$. The knockdown of $\mathrm{G}_{\mathrm{z}}$ caused an increase of cAMP levels to $131 \% \pm 6.9 \%$ over control, suggesting a partial role of $\mathrm{G}_{\mathrm{z}}$ for the increase of cAMP levels. However, knockdown of $G_{z}$ had no effect on the IUDRC.

When $\mathrm{G}_{\mathrm{i} 1}, \mathrm{G}_{\mathrm{i} 2}, \mathrm{G}_{\mathrm{i} 3}$, and $\mathrm{G}_{\mathrm{o} 1}$ were knocked down individually, the decrease in cAMP at $100 \mathrm{mU} / \mathrm{ml}$ TSH was not inhibited with significance despite sufficient knockdown efficiency. Since the individual $\mathrm{G}_{\mathrm{i} / \mathrm{o}}$ proteins might have potentially overlapping functions and the TSHR might not have a preference for one $\mathrm{G}_{\mathrm{i} / \mathrm{o}}$ protein isoform, we decided to co-knockdown $\mathrm{G}_{\mathrm{i} 1}, \mathrm{G}_{\mathrm{i} 2}, \mathrm{G}_{\mathrm{i} 3}$, and $\mathrm{G}_{\mathrm{o} 1}$ proteins. The knockdown efficiency for $\mathrm{G}_{\mathrm{i} 1}, \mathrm{G}_{\mathrm{i} 2}, \mathrm{G}_{\mathrm{i} 3}$, and $\mathrm{G}_{\mathrm{o} 1}$ was $57.4 \% \pm 2.7 \%, 82.0 \% \pm 3.1 \%$, $57.4 \% \pm 5.3 \%$, and $64.6 \% \pm 2.1 \%$, respectively. Figure $5 \mathrm{C}$ shows that co-knockdown of $\mathrm{Gi}_{(1,2,3} / \mathrm{G}_{01}$ proteins increased cAMP levels stimulated by $100 \mathrm{mU} / \mathrm{ml}$ TSH from $55.3 \% \pm$ $1.6 \%$ to $72.5 \% \pm 2.5 \%$ of the peak level.

\section{Discussion}

We observed that TSHR activation by TSH or thyrostimulin to regulate cAMP production in HEK-TSHR cells generated an IUDRC (Fig. 1). Low doses of TSH induce $\mathrm{G}_{\mathrm{s}}$-mediated increases of cAMP while high TSH doses lead to a $\mathrm{G}_{\mathrm{i} / \mathrm{o}}$-mediated cAMP decreases. It is of note that in vitro cell systems like HEKTSHR cells are less sensitive to TSH than thyrocytes in humans and the potency of TSH is shifted to higher doses. This has been reported in many studies. Nevertheless, in vitro studies using high doses of TSH have been found to be good models of TSH action in humans.

The source of bTSH was important for the ability to observe an IUDRC and might explain why the biphasic response for cAMP has not been reported previously. bTSH used in this study was purchased from Millipore and this TSH preparation is more potent than bTSH from Sigma, which we and others have used previously (Supplemental Fig. 3). bTSH from Sigma indicates an IUDRC at the highest dose, but we hypothesize that the improved potency of bTSH from Millipore permitted identification and characterization of the biphasic curve and the contributing signaling molecules.
A

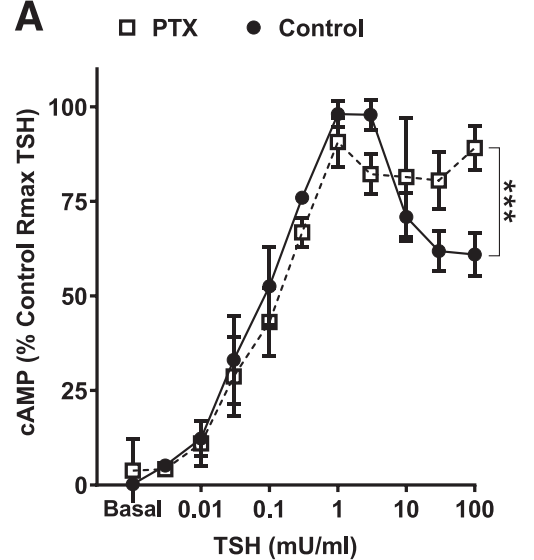

B

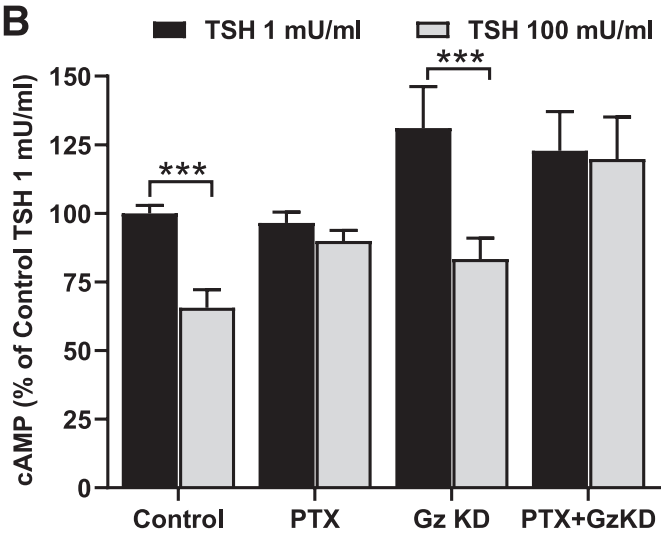

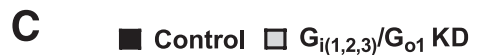

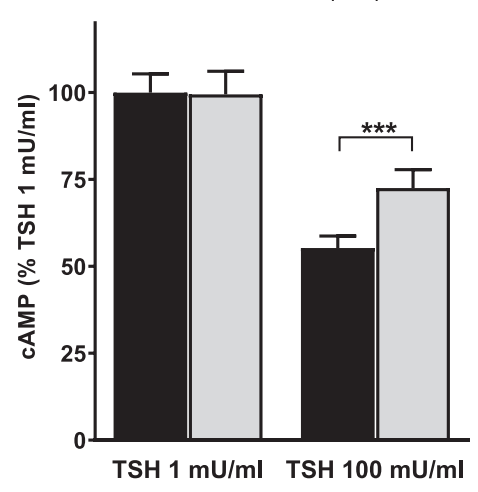

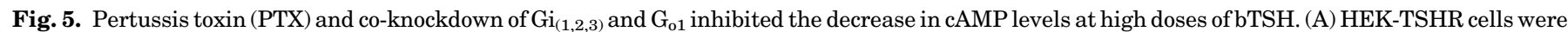

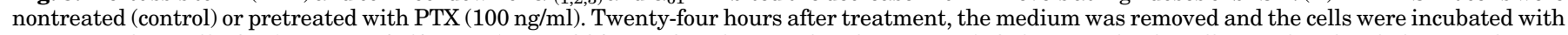

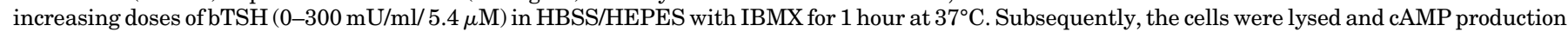

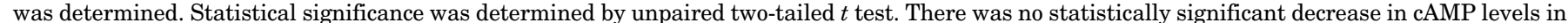

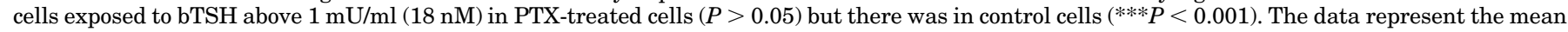

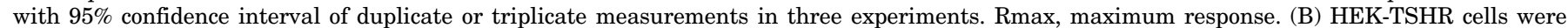

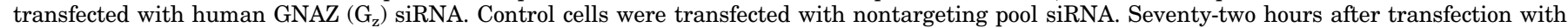

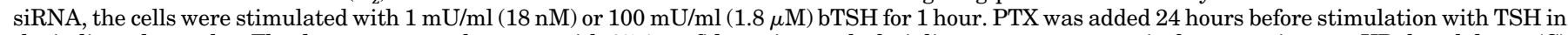

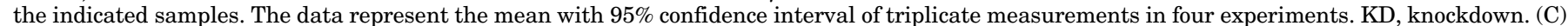

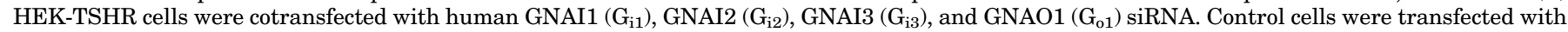

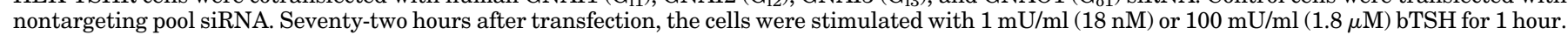

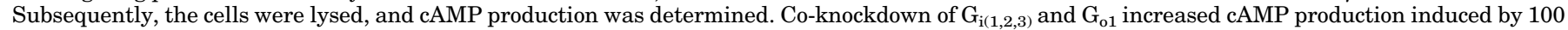

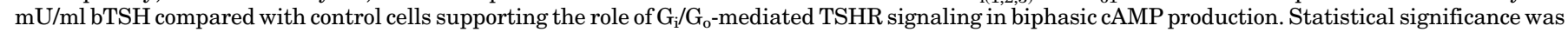

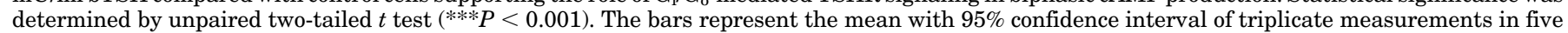
experiments. 
In HEK-TSHR cells, rhTSH and bTSH have almost overlapping potencies for the first part of the curve at low TSH doses $\left(\mathrm{EC}_{50}\right.$ values for bTSH and rhTSH are 2.5 and $1 \mathrm{nM}$, respectively). It has been reported that bTSH has a higher affinity for the human TSHR and a 6- to 10-fold higher intrinsic activity than hTSH (Thotakura et al., 1991; EastPalmer et al., 1995; Yamazaki et al., 1995; Mueller et al., 2009). Our data do not support this widely accepted statement. The differences in the data could have resulted from the fact that most studies that showed a difference in potency were performed with pituitary human TSH (National Hormone and Pituitary Program). In contrast to previous studies, we used rhTSH (Thyrogen), which is FDA approved for use in patients. It has been demonstrated that the TSHR-mediated increase in cAMP production is mediated by $\mathrm{G}_{\mathrm{s}}$ activation of adenylyl cyclase (Allgeier et al., 1994; Paschke and Ludgate, 1997). We confirmed in HEK-TSHR cells by $\mathrm{G}_{\mathrm{s}}$ knockdown that the increasing levels of cAMP at low doses of TSH were mediated through activation of $\mathrm{G}_{\mathrm{s}}$ (Fig. 2). Moreover, we demonstrated that the decrease in cAMP levels at high doses of TSH $(>1 \mathrm{mU} / \mathrm{ml})$ was caused by a decrease in cAMP production and not by increased cAMP degradation as inhibition of cyclic nucleotide phosphodiesterases had no effect. The decreased cAMP levels at high doses may have been caused by homologous desensitization mediated by $\beta$-arrestin 1 or 2 , heterologous desensitization mediated by protein kinase A, receptor downregulation, or $\mathrm{G}_{\mathrm{i} / \mathrm{o}}$ inhibition of adenylyl cyclase. We showed that protein kinase A inhibition by $\mathrm{H}-89$ and downregulation of $\beta$-arrestin 1 and $\beta$-arrestin 2 by siRNA did not affect the decreased cAMP levels at high TSH doses in the biphasic curve. We found that high doses of TSH caused a decrease in cell surface TSHRs, but that inhibition of TSHR downregulation by overexpression of a dominant negative dynamin 1 mutant in combination with siRNA knockdown of $\beta$-arrestin 2 (Frenzel et al., 2006; Boutin et al., 2014) did not affect the decreased cAMP production (Fig. 4). By contrast, pretreatment with PTX, which inhibits activation of $G_{i} / G_{o}$ proteins, inhibited the decrease in cAMP levels at high TSH doses and led to complete recovery of cAMP production (Fig. 5). The PTX effect strongly indicated a role of $G_{i}$ and $G_{o}$ proteins, and, therefore, we attempted to knock down $G_{i} / G_{0}$ proteins individually. The individual knockdown of $G_{i 1}, G_{i 2}$, $\mathrm{G}_{\mathrm{i} 3}$, or $\mathrm{G}_{01}$ proteins did not show a significant effect on the second phase of the cAMP curve, which might have been the result of overlapping functions of the $G_{i} / G_{o}$ isoforms. Therefore, a co-knockdown of all three $G_{i}$ proteins and $G_{01}$ protein was carried out. Co-knockdown of $\mathrm{G}_{\mathrm{i}(1,2,3)}$ and $\mathrm{G}_{\mathrm{o} 1}$ partially inhibited the decrease in cAMP production at high doses of TSH. The co-knockdown, however, did not allow optimal knockdown efficiency of the individual $G_{i}$ and $G_{o}$ proteins and could explain why PTX completely inhibited but the co-knockdown of $\mathrm{G}_{\mathrm{i}(1,2,3} / \mathrm{G}_{01}$ only partially inhibited the decreasing part of the biphasic curve. Thus, we concluded that the decrease in the biphasic regulation of cAMP production by TSHR was mediated by $\mathrm{G}_{\mathrm{i}} / \mathrm{G}_{\mathrm{o}}$ activation.

It is interesting that we found a time dependency to the decrease in cAMP production caused by high doses of TSH (Fig. 3). That is, a high dose of TSH $(100 \mathrm{mU} / \mathrm{ml})$ initially caused a robust increase in cAMP that was greater than that caused by a low dose of TSH $(1 \mathrm{mU} / \mathrm{ml})$ but that with time exposure to $100 \mathrm{mU} / \mathrm{ml}$ TSH caused the rate of production to decrease to less than the rate caused by $1 \mathrm{mU} / \mathrm{ml}$. This may have been caused by competition of binding of activated TSHRs to $G_{\mathrm{s}}$ versus $\mathrm{G}_{\mathrm{i} / \mathrm{o}}$ that may favor $\mathrm{G}_{\mathrm{s}}$ at early times as has been shown in other GPCR systems (see below).

Nonmonotonic dose responses have been found in many receptor systems including GPCRs (Conolly and Lutz, 2004; Calabrese, 2013). Several different mechanisms may mediate these effects. This was usually found when an agonist would activate two GPCR subtypes. For example, in adult rat striatum, adenylate cyclase activity was decreased by low doses of phenylpropyladenosine via adenosine $A_{1}$ receptor and increased by high doses via adenosine $\mathrm{A}_{2}$ receptors (Ebersolt et al., 1983). By contrast, activation of a single bombesin receptor, the $\mathrm{BB}_{3}$ receptor, exhibited an IUDRC to stimulate inositoltrisphosphate production when activated by some agonists (Moreno et al., 2013). Indeed, a number of GPCRs have been shown to couple to more than one type of $G$ protein, including to $\mathrm{G}_{\mathrm{s}}$ and $\mathrm{G}_{\mathrm{i} / \mathrm{o}}$ proteins (Rashid et al., 2004; Woehler and Ponimaskin, 2009). For some GPCRs, the coupling to $G_{s}$ and $\mathrm{G}_{\mathrm{i}}$ proteins was sequential. For example, both the $\beta_{2^{-}}$ adrenoceptor (Daaka et al., 1997) and the $\beta_{3}$-adrenoceptor have been shown to couple to $G_{\mathrm{s}}$ and then to $\mathrm{G}_{\mathrm{i}}$ (Hadi et al., 2013). For the $\beta_{2}$-adrenoceptor, sequential coupling was shown to be dependent on receptor phosphorylation (Daaka et al., 1997). Of note is that simultaneous activation of $G_{s}$ and $\mathrm{G}_{\mathrm{i}}$ to regulate cAMP production by a single GPCR at different doses of agonist has been reported previously, however, the coupling to $G$ proteins was reversed at different doses of agonist than we have found. For the $\alpha_{2}$-adrenoceptor, low doses of UK-14304 caused inhibition of adenylate cyclase activity by coupling to $G_{i}$ and stimulation of adenylate cyclase activity at high doses via $\mathrm{G}_{\mathrm{s}}$ (Eason et al., 1992). We previously reported that TSHR can bind to and activate $\mathrm{G}_{\mathrm{s}}$ to stimulate cAMP production at low TSH doses and to $\mathrm{G}_{\mathrm{q} / 11}$ to stimulate inositol-1,4,5-trisphosphate production at high doses of TSH (Allen et al., 2011). Our present findings show that high doses of TSH allow TSHR to couple to $\mathrm{G}_{\mathrm{i} / \mathrm{o}}$ proteins also and thereby regulate cAMP production in a biphasic manner. We concluded in our previous study that high TSH doses allowed binding to more than one protomer of a TSHR oligomer and that this led to a conformational change that allowed coupling to $G_{q / 11}$, and we suggest this mechanism for $G_{i / o}$ also.

In summary, we showed that the TSHR-mediated IUDRC for cAMP production involves coupling to different $G$ proteins at different doses of agonist. Specifically, TSHR couples to $G_{s}$ at low TSH doses and to $\mathrm{G}_{\mathrm{i} / \mathrm{o}}$ at high TSH doses. We suggest that the biphasic cAMP response allows TSHR to mediate responses at lower levels of TSH or thyrostimulin and that decreased cAMP production at high doses may represent a mechanism to prevent overstimulation of TSHR-expressing cells. In particular, this biphasic cAMP response might be of importance for the regulation of thyroid specific genes in thyrocytes that are partly regulated by cAMP production, and this mechanism could prevent chronic stimulation of thyroid gland function.

\section{Acknowledgments}

We thank Dr. Paul Banga (King's College London, UK) for kindly providing us with the TSHR antibody KSAb1. We are also grateful for the contributions of Brianna Daley and Andrew Tobey of the Metabolic Disease Branch, National Institute of Diabetes and Digestive and Kidney Diseases, National Institutes of Health, Bethesda, MD, who provided us with thyroid tissue. 


\section{Authorship Contributions}

Participated in research design: Neumann, Krieger, Gershengorn. Conducted experiments: Neumann, Malik, Marcus-Samuels, Eliseeva, Jang, Krieger.

Performed data analysis: Neumann, Malik, Marcus-Samuels, Eliseeva, Jang, Krieger, Gershengorn.

Wrote or contributed to the writing of the manuscript: Neumann, Malik, Klubo-Gwiezdzinska, Gershengorn.

\section{References}

Allen MD, Neumann S, and Gershengorn MC (2011) Occupancy of both sites on the thyrotropin (TSH) receptor dimer is necessary for phosphoinositide signaling. FASEB J 25:3687-3694.

Allgeier A, Offermanns S, Van Sande J, Spicher K, Schultz G, and Dumont JE (1994) The human thyrotropin receptor activates G-proteins Gs and Gq/11. J Biol Chem 269:13733-13735.

Boutin A, Eliseeva E, Gershengorn MC, and Neumann S (2014) B-Arrestin-1 mediates thyrotropin-enhanced osteoblast differentiation FASEB $J \mathbf{2 8}$ 3446-3455.

Calabrese EJ (2013) Biphasic dose responses in biology, toxicology and medicine: accounting for their generalizability and quantitative features. Environ Pollut 182 $452-460$

Calabrese EJ (2018) Hormesis: path and progression to significance. Int $J$ Mol Sci 19:E2871.

Casey PJ, Fong HK, Simon MI, and Gilman AG (1990) Gz, a guanine nucleotidebinding protein with unique biochemical properties. $J$ Biol Chem 265:2383-2390.

Conolly RB and Lutz WK (2004) Nonmonotonic dose-response relationships: mechanistic basis, kinetic modeling, and implications for risk assessment. Toxicol Sci 77:151-157.

Daaka Y, Luttrell LM, and Lefkowitz RJ (1997) Switching of the coupling of the beta2-adrenergic receptor to different G proteins by protein kinase A. Nature $\mathbf{3 9 0}$ $88-91$.

Eason MG, Kurose H, Holt BD, Raymond JR, and Liggett SB (1992) Simultaneous coupling of alpha 2-adrenergic receptors to two G-proteins with opposing effects. Subtype-selective coupling of alpha $2 \mathrm{C} 10$, alpha $2 \mathrm{C} 4$, and alpha $2 \mathrm{C} 2$ adrenergic receptors to $\mathrm{Gi}$ and Gs. J Biol Chem 267:15795-15801.

East-Palmer J, Szkudlinski MW, Lee J, Thotakura NR, and Weintraub BD (1995) A novel, nonradioactive in vivo bioassay of thyrotropin (TSH). Thyroid 5:55-59.

Ebersolt C, Premont J, Prochiantz A, Perez M, and Bockaert J (1983) Inhibition of brain adenylate cyclase by $\mathrm{A} 1$ adenosine receptors: pharmacological characteristics and locations. Brain Res 267:123-129.

Frenzel R, Voigt C, and Paschke R (2006) The human thyrotropin receptor is predominantly internalized by beta-arrestin 2. Endocrinology 147:3114-3122.

Hadi T, Barrichon M, Mourtialon P, Wendremaire M, Garrido C, Sagot P, Bardou M, and Lirussi F (2013) Biphasic Erk1/2 activation sequentially involving Gs and Gi signaling is required in beta3-adrenergic receptor-induced primary smooth muscle cell proliferation. Biochim Biophys Acta 1833:1041-1051.

Hara T, Namba H, Takamura N, Yang TT, Nagayama Y, Fukata S, Kuma K, Ishikawa N, Ito K, and Yamashita S (1999) Thyrotropin regulates c-Jun N-terminal kinase (JNK) activity through two distinct signal pathways in human thyroid cells. Endocrinology 140:1724-1730.
Jamshidi RJ, Jacobs BA, Sullivan LC, Chavera TA, Saylor RM, Prisinzano TE, Clarke WP, and Berg KA (2015) Functional selectivity of kappa opioid receptor agonists in peripheral sensory neurons. J Pharmacol Exp Ther 355:174-182.

Karponis D and Ananth S (2017) The role of thyrostimulin and its potential clinical significance. Endocr Regul 51:117-128.

Laugwitz KL, Allgeier A, Offermanns S, Spicher K, Van Sande J, Dumont JE, and Schultz G (1996) The human thyrotropin receptor: a heptahelical receptor capable of stimulating members of all four G protein families. Proc Natl Acad Sci USA 93:116-120

Moreno P, Mantey SA, Nuche-Berenguer B, Reitman ML, González N, Coy DH and Jensen RT (2013) Comparative pharmacology of bombesin receptor subtype-3, nonpeptide agonist MK-5046, a universal peptide agonist, and peptide antagonist Bantag-1 for human bombesin receptors. J Pharmacol Exp Ther 347:100-116.

Mueller S, Kleinau G, Szkudlinski MW, Jaeschke H, Krause G, and Paschke R (2009) The superagonistic activity of bovine thyroid-stimulating hormone (TSH) and the human TR1401 TSH analog is determined by specific amino acids in the hinge region of the human TSH receptor. J Biol Chem 284:16317-16324.

Nakabayashi K, Matsumi H, Bhalla A, Bae J, Mosselman S, Hsu SY, and Hsueh AJ (2002) Thyrostimulin, a heterodimer of two new human glycoprotein hormone subunits, activates the thyroid-stimulating hormone receptor. J Clin Invest 109: $1445-1452$.

Neumann S, Kleinau G, Costanzi S, Moore S, Jiang JK, Raaka BM, Thomas CJ, Krause G, and Gershengorn MC (2008) A low-molecular-weight antagonist for the human thyrotropin receptor with therapeutic potential for hyperthyroidism. Endocrinology 149:5945-5950.

Paschke R and Ludgate M (1997) The thyrotropin receptor in thyroid diseases. N Engl J Med 337:1675-1681.

Rashid AJ, O'Dowd BF, and George SR (2004) Minireview: diversity and complexity of signaling through peptidergic G protein-coupled receptors. Endocrinology 145: 2645-2652.

Riters LV, Pawlisch BA, Kelm-Nelson CA, and Stevenson SA (2014) Inverted-U shaped effects of D1 dopamine receptor stimulation in the medial preoptic nucleus on sexually motivated song in male European starlings. Eur $J$ Neurosci 39:650-662.

Song BD, Yarar D, and Schmid SL (2004) An assembly-incompetent mutant establishes a requirement for dynamin self-assembly in clathrin-mediated endocytosis in vivo. Mol Biol Cell 15:2243-2252.

Thotakura NR, Desai RK, Bates LG, Cole ES, Pratt BM, and Weintraub BD (1991) Biological activity and metabolic clearance of a recombinant human thyrotropin produced in Chinese hamster ovary cells. Endocrinology 128:341-348.

Vandenberg LN, Colborn T, Hayes TB, Heindel JJ, Jacobs DR Jr, Lee DH, Shioda T, Soto AM, vom Saal FS, Welshons WV, et al. (2012) Hormones and endocrinedisrupting chemicals: low-dose effects and nonmonotonic dose responses. Endocr Rev 33:378-455.

Woehler A and Ponimaskin EG (2009) G protein--mediated signaling: same receptor multiple effectors. Curr Mol Pharmacol 2:237-248.

Yamazaki K, Sato K, Shizume K, Kanaji Y, Ito Y, Obara T, Nakagawa T, Koizumi T, and Nishimura R (1995) Potent thyrotropic activity of human chorionic gonadotropin variants in terms of $125 \mathrm{I}$ incorporation and de novo synthesized thyroid hormone release in human thyroid follicles. J Clin Endocrinol Metab 80:473-479.

Address correspondence to: Dr. Marvin C. Gershengorn, National Institutes of Health, NIDDK, 50 South Dr., Building 50, Room 4134, Bethesda, MD 20892. E-mail: MarvinG@intra.niddk.nih.gov 